\title{
The gaps in satisfaction with transit services among BRT, metro, and bus riders: Evidence from Guangzhou
}

\author{
Jason Cao \\ University of Minnesota \\ cao@umn.edu \\ Chen Zhang \\ University of Minnesota \\ zhan3373@umn.edu
}

\author{
Xiaoshu Cao \\ Sun Yat-Sen University \\ caoxsh@mail.sys.edu.cn \\ Xiaoyan Huang
Shaanxi Normal University
hxiaoy@snnu.edu.cn
}

\begin{abstract}
This paper explores transit riders' satisfaction with bus rapid transit (BRT) and compares BRT with conventional bus and metro services using revealed preference data from Guangzhou, China. A trivariate ordered probit model is developed to examine the effects of various service attributes on riders' overall satisfactions with the three types of transit. We find that the top-three influential attributes for satisfaction with BRT are ease of use, safety while riding, and comfort while waiting. Moreover, transit riders are most satisfied with metro, followed by BRT and conventional bus. The top-five attributes that contribute to the difference in the overall satisfaction between BRT and metro are ease of use, comfort while riding, convenience of service, travel time, and comfort while waiting. Based on the findings, we propose specific strategies that can be used to enhance BRT quality of service.
\end{abstract}

Keywords: Bus rapid transit (BRT), rail transit, customer satisfaction, quality of service, transport policy

\section{Article history:}

Received: November 29, 2013

Accepted: December 14, 2014

Available online: July 10, 2015

\section{$1 \quad$ Introduction}

Bus rapid transit (BRT) investments have proliferated worldwide during the past few decades. According to the data from Global BRT (www.brtdata.org, accessed on October 1, 2013), 163 cities have implemented BRT or priority bus systems. The vast majority of the systems commenced after 2000. The length of all systems totals more than 4,200 kilometers and daily ridership exceeds 29 million. The popularity of BRT is partly attributable to its ability to combine the quality of rail transit and the flexibility of conventional bus (Levinson et al. 2003a). Because BRT is often characterized as a low-cost "rail-like" rapid transit (Levinson et al. 2003a), it becomes an alternative to rail transit.

BRT is expected to create a new image distinct from conventional bus (Levinson et al. 2003b), which helps attract choice riders (who have the option to drive but choose to ride transit) and reduce

Copyright 2015 Jason Cao, Xiaoshu Cao, Chen Zhang, and Xiaoyan Huang

http://dx.doi.org/10.5198/jtlu.2015.592

ISSN: 1938-7849 | Licensed under the Creative Commons Attribution - Noncommercial License 3.0

The Journal of Transport and Land Use is the official journal of the World Society for Transport and Land Use (WSTLUR) and is published and sponsored by the University of Minnesota Center for Transportation Studies. This paper is also published with sponsorship from WSTLUR and the Institutes of Transportation Studies at the University of California, Davis, and the University of California, Berkeley. 
the growth in congestion. The image of a product/service is what a consumer uses to distinguish it from others. A strong image may affect customers' predisposition toward the product/service, which ultimately changes their consumption behavior. For example, automakers spend billions of dollars each year on car advertisement to portray the image of comfort, status, and lifestyle, beyond the functionality of their vehicles (Cain et al. 2009). Although conventional bus is regarded as a green service and riders can socialize with other passengers as well as use their travel time productively, it often carries a negative image compared to personal automobile: slow, unreliable, inconvenient, uncomfortable, and unsafe (Luck 2001; TCRP 2000). Sometimes, conventional bus suffers from a severe income and racial stigma, particularly in the United States (Garrett and Taylor 1999). In contrast, BRT is "a flexible, rubber-tired rapid-transit mode that combines stations, vehicles, services, running ways, and intelligent transportation system (ITS) elements into an integrated system with a strong positive identity that evokes a unique image" (Levinson et al. 2003b).

To establish an identity distinctive from conventional bus, transit agencies often enhance BRT's quality of service from several perspectives (Cain et al. 2009). BRT is designated as a high-frequency and all-day service. It operates on highway shoulders, median busways, dedicated right-of-way, or arterials with signal priority to enhance speed and reliability. Its dwell time is minimized through advanced fare collection, level and multi-door boarding (as is done in many rail systems). BRT is stylized with sleek and rail-like vehicles with high capacity, "aerodynamic design," "panoramic windows," enhanced seating and interior design (p. 19). BRT stations are designed according to the standard of rail transit, with a variety of amenities such as traveler's information system, shelters, enhanced lighting, and security. For branding, the livery and icon of BRT are consistent with rail transit if they coexist or are distinguished from conventional bus. Overall, BRT is often characterized as a train on rubber tires.

Several questions then emerge: Will BRT deliver the same quality of service as rail transit? Will it perform better than conventional bus? If the budget for BRT investments is limited, what kind of service attributes should be prioritized for the sake of improving quality of service? According to TCRP Report 100, quality of service reflects the performance of transit service from the passenger's point of view. It is often measured through a customer satisfaction survey (TCRP 2003).

Previous studies have identified a variety of service attributes related to service quality of transit. They include, but are not limited to, service availability, passengers, reliability, travel time, safety and security, appearance and comfort (TCRP 2003). However, few have investigated service attributes that specifically influence BRT's quality of service. Baltes (2003) conducts user surveys on South MiamiDade BRT and Orlando BRT. He asks respondents to report their satisfactions with service attributes and overall satisfaction with BRT. Then he develops regression models to assess which attributes help improve the overall satisfaction. He concludes that comfort, travel time, reliability, and safety are important attributes for Orlando BRT, while service frequency, travel time, seat availability, convenience, hours of service, safety on bus, and dependability are influential factors for South Miami-Dade BRT. However, linear regression was not an appropriate model because the overall satisfaction was measured using a five-point ordinal scale. Several studies also evaluate riders' satisfaction with various service attributes and overall satisfaction with BRT (Adebambo and Adebayo 2009; Deng and Nelson 2012; Mahmoudi et al. 2010). However, they do not identify service attributes that enhance the overall satisfaction. Accordingly, the literature offers practitioners little empirical evidence on the priority of service improvement.

Most studies on riders' satisfaction focus on a single type of transit and few conduct a comparative analysis of different types. Tyrinopoulos and Antoniou (2008) examine service attributes that influence riders' satisfaction with different transits (including bus, trolley bus, and rail) in two Greek cities. Ordered logit models show that for all transits, the top-three influential attributes are service frequency, 
vehicle cleanliness, and waiting conditions. They also find that different service attributes are associated with different transits, and the importance of service attributes for different transits also varies. Nevertheless, they do not indicate which type of transit offers a better quality of service than others. Ben-Akiva and Morikawa (2002) explore whether people prefer rail over bus transit and what service attributes contribute to the difference in the preference. Using a revealed preference dataset from Washington DC, this study develops a mode choice model with access time, wait time, transfer time, running time, and transit fare (among others) being independent variables. It finds that the coefficients for the service variables are the same across different transits: metro, commuter rail, express bus, and local bus. It concludes that although metro is the most preferred mode, there are no substantial differences between bus and metro for zero-vehicle households. The study further analyzes a stated preference dataset from Boston and concludes no difference in the preference between rail and bus, after controlling for wait time, running time, transfer, and travel time reliability.

Few studies have compared quality of service between BRT and conventional bus/rail transit. Currie (2005) reviews the literature and summarizes how people value trip attributes for different transits. For transit time and fare, planners do not estimate alternative-specific coefficients for different transits in mode choice models, so the study infers that passengers value the attributes in the same way. It also compares "the user-perceived attractiveness of one transit mode compared to another, excluding the influence of factors such as fare, walk time, wait time, in-vehicle travel time, and the need to transfer" and finds that there is no difference between BRT and rail. Overall, Currie concludes that BRT is as effective as rail transit in improving ridership and the former is more cost-effective than the latter. This study focuses on a few key attributes used in mode choice models and does not explore intangible factors such as comfort and convenience. Cain et al. (2009) surveys riders of metro, light rail transit, BRT, and conventional bus (as well as non-transit-riders) in Los Angeles. The study asks respondents to indicate their perceptions of 14 service attributes and their overall opinion of each transit service, even if they have not used the service before. They develop separate regression models to evaluate which attributes improve the overall satisfaction. This study represents a significant improvement in research design. However, its analysis is flawed in three aspects. First, ordered models are appropriate tools since the overall satisfaction was measured on ordinal scales. Second, because service attributes have different means and standard deviations, it is inappropriate to evaluate the importance of independent variables based on unstandardized coefficients. Third, since riders rate different types of transit simultaneously, unobserved factors may jointly influence their ratings. That is, the error terms of different regression equations may not be independent. A seemingly unrelated approach should have been adopted. Overall, there are significant gaps on comparative advantages of BRT over other types of transit.

Using Guangzhou BRT, we fill the gaps by investigating the relationships between service attributes and quality of service. We aim to answer the following two sets of questions:

- What kind of service attributes significantly contribute to the overall satisfaction with transit? Which are the most important among the significant attributes? Do they differ among BRT, metro, and conventional bus?

- Are there any differences among the overall satisfactions with different types of transit? If yes, what service attributes contribute to the disparities? What is the relative importance among the significant attributes?

The organization of this study is as follows. Section 2 introduces the background of Guangzhou BRT and describes data collection. Section 3 presents the results. The final section summarizes the key results and offers implications for planning practice. 


\section{$2 \quad$ Methodology}

\subsection{Guangzhou BRT}

Guangzhou, internationally well-known as Canton, is the capital city of Guangdong province in South China. It is 120 kilometers northwest of Hong Kong. It had about 13 million people in 2010 and is the third largest city in China. Guangzhou has a relatively balanced mode share. In 2005, walking and biking accounted for 47 percent, automobiles and motorcycles shouldered 25 percent, and transit shared 25 percent.

Guangzhou BRT commenced in 2010. It operates on the dedicated innermost lanes along Zhongshan Avenue, which is located in the central business district. It has 26 stations starting at Tianhe Sports Center and ending at Xiayuan. The line serves 31 regular BRT routes, and five express routes and six short routes during peak hours. Among them, one route runs exclusively on the dedicated lanes. Other BRT routes share bus-only lanes with other buses when they run outside Zhongshan Avenue. Guangzhou BRT has the highest service frequency throughout the world: 350 buses per hour in a single direction. It has the second highest average daily ridership (843,000 passengers) after Bogota's TransMilenio (1.65 million passengers) (http://www.chinabrt.org/cn/cities/param-quan.aspx?param=20, accessed on Sept. 25, 2014).

Guangzhou BRT received a "Gold" ranking from the Institute for Transportation and Development in 2010. Its featuring attributes include dedicated right-of-way with transit signal priority; enhanced station with shelters, benches, and real-time traveler information displays; advanced pre-board fare collection systems; level boarding and multi-door boarding; improved security through surveillance at stations and on board; next stop announcements; and integration with other modes such as bus, metro, and bike-sharing. These attributes play an important role in creating a positive image.

\subsection{Sampling and data}

The BRT data were collected from riders at the 20 stations from Sports Center to Huangpu Coach Station in July and August 2013 (Figure 1). The corridor is served by all three types of transit: BRT, conventional bus, and metro. Since we will compare customer satisfaction of the three transits, we administered the same survey to riders at metro stations and bus stops in the corridor while we were collecting data from BRT riders. Table 1 illustrates some characteristics of the three types of transit in the corridor. Flat fare is applied to conventional bus and BRT, whereas metro fare is distance-based. All three types of transit start operation almost at the same time, but bus has extended night owl hours, compared with BRT and metro. All three transits are high-frequency services, even during nonpeak hours. Metro service is the most frequent, followed by BRT and then bus. Transit operating speed, passenger load, and on-time performance follow the same pattern; metro ranks the best and bus ranks the lowest. 
Table 1: Transit service attributes

\begin{tabular}{|l|l|l|l|}
\hline Characteristics & Bus & BRT & Metro \\
\hline Fare (Yuan) & 2 & 2 & $\begin{array}{l}\text { 2-9 based on trip } \\
\text { distance }\end{array}$ \\
\hline Service span & $5: 30$ a.m. to 1:40 a.m. & 6 a.m to 11 p.m. & 6 a.m. to 11:30 p.m. \\
\hline Headway (minute) & 6-10 & $\begin{array}{l}\text { Peak hours: } 5 \\
\text { Nonpeak hours: on } \\
\text { average 6.7 }\end{array}$ & $\begin{array}{l}\text { Peak hours: 3-4.5 } \\
\text { Nonpeak hours: 4.5-7.5 }\end{array}$ \\
\hline $\begin{array}{l}\text { Operating speed (km/ } \\
\text { hour) }\end{array}$ & $\begin{array}{l}\text { Peak hours: 11-13 } \\
\text { Nonpeak hours: } 15-20\end{array}$ & $\begin{array}{l}\text { Peak hours: } 21 \\
\text { Nonpeak hours: 33 }\end{array}$ & 50-60 \\
\hline Peak hour passenger load & Very crowded & $\begin{array}{l}\text { Crowded but better } \\
\text { than bus }\end{array}$ & $\begin{array}{l}\text { Extremely crowded } \\
\text { (crash load) }\end{array}$ \\
\hline On-time performance & Worst & Good & Best \\
\hline
\end{tabular}

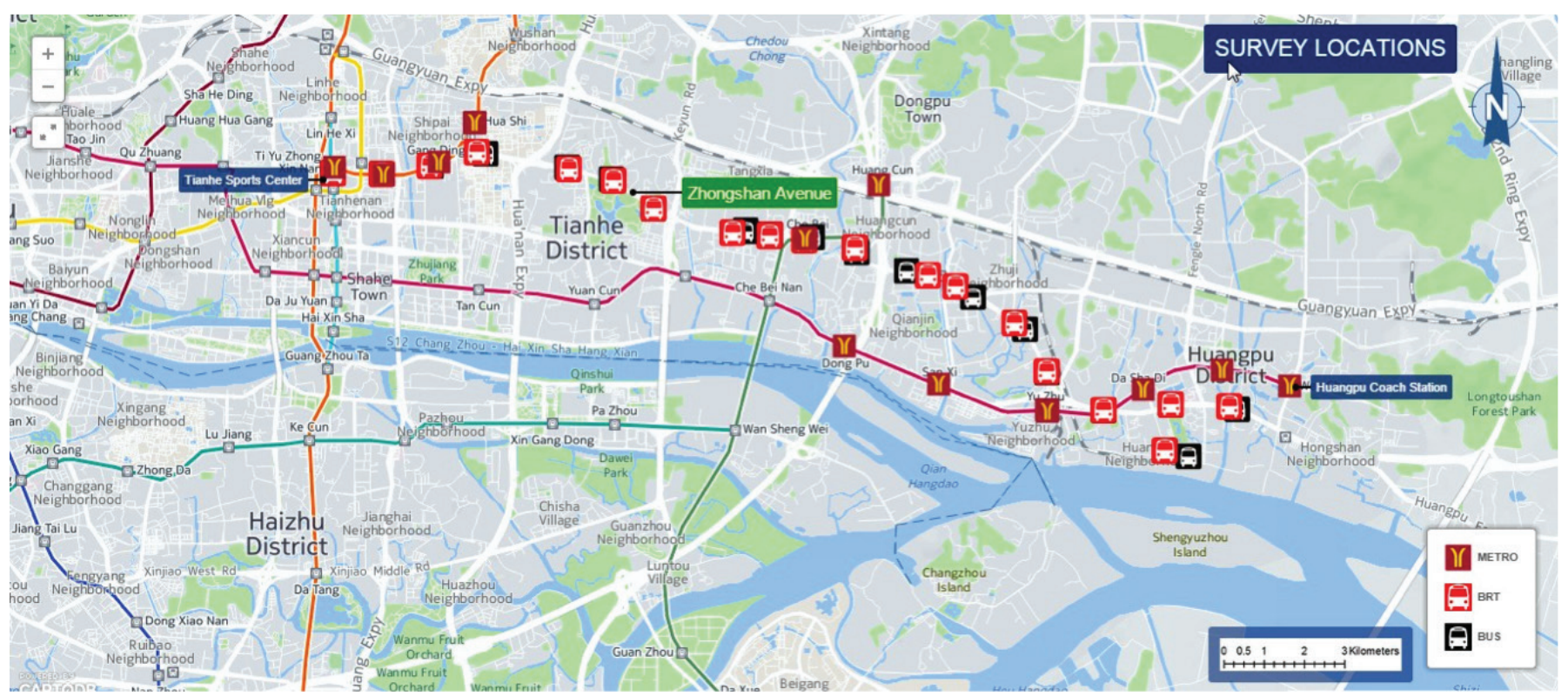

Figure 1: Survey locations (Sources: Google Maps, Baidu Maps, 2014)

Since BRT is implemented primarily to mitigate congestion, we chose to survey riders from morning peak to evening peak during weekdays. Undergraduate and graduate students of a few universities in Guangzhou administered the survey after appropriate training. The surveyors randomly chose passengers at stations/stops and briefly explained the survey purpose while handing out the cover letter. Respondents were then asked to fill out the questionnaire after their consent. The surveyors answered clarification questions when asked. We asked the surveyor to board with passengers if they were unable to complete the survey while waiting.

The four-page survey includes three sections. In Section A, we ask respondents to report their transit use and information related to their ongoing trip including origin and destination, distance, modes of access/egress, travel time, and cost. Section B contains a list of socio-demographics including gender, age, education, driver's license, employment status, income, household size, and car ownership. In Sec- 
tion C, we adapt questions designed by Cain et al. (2009). The questions are based on literature review and a focus-group study. In particular, we ask respondents to indicate the importance of 14 attributes in affecting whether or not they use transit. For each of the three transit types, respondents are then asked to rate the attributes and to indicate their overall opinion of transit service on a five-point ordinal scale ranging from "very poor" (1) to "very good" (5). They are asked to offer their impression even if they have not used a particular transit before. The 14 attributes cover different dimensions of quality of service, which include door-to-door travel time, safety while at station/stop (safety from accidents and/ or crime), avoid stress/cost of car use (traffic, parking, accidents, tickets, etc.), travel cost (transit fares, related cost like parking and rickshaw/taxi), frequency of service (how often service runs), comfort while riding (seats available, temperature, smooth ride, cleanliness, etc.), hours of service (how early or late service runs, and/or weekend hours), other riders (feeling secure/at ease/compatible with other riders), convenience of service (goes where you need to go/parking availability), customer service (provided by drivers and other transit service staff), reliability of service (does the service run on time?), ease of use (clear service info, routes easy to figure out, etc.), comfort while waiting at station/stop (shelter from weather, amenities, etc.), and safety while riding the service (safety from accidents and/or crime). The overall opinion is an indicator of customer satisfaction with transit as a whole. The survey instrument is administered in Chinese. It was pretested by transit riders at stations/stops in Shenzhen and Guangzhou. We revised the survey based on their feedback.

When administering the survey, our sampling target was to achieve an equal number of riders for each type of transit. The final data include 492 BRT riders, 499 bus riders, and 482 metro riders. Table 2 compares their socio-demographic characteristics. Household size and income are significantly different among riders of different transits. Bonferroni tests show that bus riders tend to have a larger household than BRT and metro riders, whereas there is no difference between the latter two, and metro riders are more affluent than bus and BRT riders, but there is no difference between the latter two.

Table 2: Sample characteristics

\begin{tabular}{|l|c|c|c|c|}
\hline Variables & \multicolumn{1}{|l|}{ Bus } & BRT & Metro & $\boldsymbol{p}$-value \\
\hline Income $^{*}$ & 4.48 & 4.71 & 4.99 & 0.000 \\
\hline Household size & 4.49 & 4.08 & 4.17 & 0.000 \\
\hline \# of cars & 0.50 & 0.51 & 0.58 & 0.162 \\
\hline \# of motorcycles & 0.50 & 0.47 & 0.48 & 0.855 \\
\hline Age & 2.77 & 2.74 & 2.70 & 0.527 \\
\hline Education * & 4.01 & 4.06 & 3.92 & 0.116 \\
\hline Female & $44 \%$ & $50 \%$ & $47 \%$ & 0.221 \\
\hline Worker & $78 \%$ & $79 \%$ & $81 \%$ & 0.562 \\
\hline License & $37 \%$ & $37 \%$ & $39 \%$ & 0.950 \\
\hline
\end{tabular}

The $p$-value is based on ANOVA test.

* The variables are measured on ordinal scales. In particular, for income, $1=$ less than 1000 Yuan, 2=1000-1999 Yuan, 3=2000-2999

Yuan, 4=3000-4999 Yuan, 5=4000-4999 Yuan, 6=5000-6999 Yuan, 7=7000-8999 Yuan, 8=more than 9000 Yuan. For age, $1=$ under $18,2=18$ to $24,3=25$ to $34,4=35$ to $44,5=45$ to $54,6=55$ to $64,7=65$ to $74,8=75$ or older. For education, $1=$ up to the sixth grade, $2=$ junior high, $3=$ senior high, $4=$ associate degree, $5=$ bachelor's degree, $6=$ graduate degree. 


\section{$3 \quad$ Results}

\subsection{Satisfaction with service}

Table 3 presents riders' overall satisfaction with transit and the rating of service attributes. Paired-sample t-tests show that for each of the variables in Table 3 , the differences between different types of transit are significant at the 0.01 level. First, the overall satisfaction of conventional bus is the lowest, followed by BRT and metro. This ranking pattern holds true for all but one service attribute. The rating of travel cost for BRT is the highest, followed by conventional bus and metro. That is, riders are most satisfied with travel cost for BRT and least satisfied with travel cost for metro. These are reasonable since BRT offers a better service than conventional bus although they have the same fixed fare. In contrast, metro fare is distance-based and is the highest among the three. Because riders of a particular service may favor the service they are currently using, we also conduct statistical tests for three subsamples: BRT riders, conventional bus riders, and metro riders. Test results (not shown) for the subsamples are the same as those for the whole sample, except for one attribute. Specifically, BRT riders perceive that travel costs for BRT and conventional bus are the same. Overall, although inferior to metro, BRT does provide a better quality of service in terms of almost all service attributes than conventional bus.

Second, the most satisfying attributes tend to be different for different types of transit. The three most satisfying attributes of BRT rated by all transit riders are travel cost, ease of use, and travel time. Travel cost, convenience and hours of service are the top three attributes for conventional bus. For metro, they are frequency of service, travel time, and comfort while waiting. The three least satisfying attributes are other riders, customer service, and comfort while riding for BRT; comfort while waiting, comfort while riding, and customer service for conventional bus; and other riders, travel cost, and customer service for metro. The rankings of comfort while riding, customer service, and other riders are consistently low for all three transits.

Table 3: Customer satisfaction with service attributes and overall service

\begin{tabular}{|c|c|c|c|c|c|c|}
\hline & \multicolumn{2}{|c|}{ BRT } & \multicolumn{2}{|c|}{ Bus } & \multicolumn{2}{|c|}{ Metro } \\
\hline & Mean & Ranking & Mean & Ranking & Mean & Ranking \\
\hline Overall satisfaction & 3.56 & & 3.03 & & 4.15 & \\
\hline Travel cost & 3.78 & 1 & 3.65 & 1 & 3.41 & 13 \\
\hline Ease of use & 3.55 & 2 & 3.14 & 5 & 4.04 & 4 \\
\hline Door-to-door travel time & 3.54 & 3 & 2.96 & 8 & 4.13 & 2 \\
\hline $\begin{array}{l}\text { Avoid stress/cost of car } \\
\text { use }\end{array}$ & 3.47 & 4 & 3.15 & 4 & 3.68 & 11 \\
\hline Frequency of service & 3.47 & 5 & 2.93 & 9 & 4.17 & 1 \\
\hline Convenience of service & 3.46 & 6 & 3.17 & 2 & 3.87 & 8 \\
\hline $\begin{array}{l}\text { Safety while at station/ } \\
\text { stop }\end{array}$ & 3.45 & 7 & 2.98 & 7 & 3.98 & 5 \\
\hline Safety while riding & 3.44 & 8 & 3.07 & 6 & 3.92 & 7 \\
\hline Hours of service & 3.41 & 9 & 3.15 & 3 & 3.85 & 9 \\
\hline Reliability of service & 3.39 & 10 & 2.92 & 10 & 3.98 & 6 \\
\hline Comfort while waiting & 3.34 & 11 & 2.81 & 14 & 4.08 & 3 \\
\hline Comfort while riding & 3.26 & 12 & 2.86 & 13 & 3.85 & 10 \\
\hline Customer service & 3.21 & 13 & 2.89 & 12 & 3.67 & 12 \\
\hline Other riders & 3.13 & 14 & 2.90 & 11 & 3.38 & 14 \\
\hline
\end{tabular}




\subsection{Factors influencing overall satisfaction}

In this subsection, we will answer the first set of questions by exploring the relative importance of different service attributes in affecting riders' overall satisfaction. Since it is measured on ordinal scales, we develop ordered models (refer to Daykin and Moffatt 2002 for an introduction to ordered probit model). Again, since riders rate conventional bus, BRT, and metro simultaneously, their overall satisfactions are likely to be jointly influenced by unobserved factors (such as their intrinsic affection toward transit), which are captured by error terms. If true, ignoring the correlations among the error terms will produce statistically consistent but inefficient estimates. One of the approaches to address this issue is to develop models using a seemingly unrelated method. Accordingly, we develop a trivariate ordered probit model using the "cmp" module in Stata 12.0 (Roodman 2011). When developing the model, we standardize the 14 attributes so that we can directly compare the relative importance of the attributes. Because riders may favor the service they are currently using, we include the dummy variables of conventional bus and metro in the model. We further include riders' socio-demographics and characteristics of their current trip to capture their influence on overall satisfactions. Insignificant variables are removed from the model to obtain a parsimonious model. However, if a variable is significant at the 0.05 level in any of the three equations, it is kept in all three equations to facilitate comparison.

Table 4 presents model results. As shown by the Rho values, the covariance of the error terms is significantly different from zero. Therefore, we should estimate the three equations jointly. Although we test all of the socio-demographic variables, none are significant. Riders who access transit by bus tend to be less satisfied with metro than those accessing by other modes, whereas riders with BRT access are more satisfied with metro than those accessing by other modes. Riders with motorcycle egress are less satisfied with BRT than those egressing by other modes. This is reasonable because motorcycle tends to offer more flexibility and independence than BRT, which has fixed route and schedules. All other trip-related characteristics are insignificant. Furthermore, bus riders are more likely to be satisfied with conventional bus service than other riders, as we expected.

Out of the 14 service attributes, 11 are significant in the model for BRT; 10 are significant for conventional bus; and 9 are significant for metro. Specifically, hours of service, travel cost, and safety while at station/stop are insignificant in any models. Service frequency is insignificant for conventional bus, whereas customer service and avoid stress/cost of car use are insignificant for metro. Among the significant attributes, the top-three important ones for BRT are ease of use, safety while riding, and comfort while waiting, and so are the ones for conventional bus. However, the top-three attributes for metro are ease of use, comfort while riding, and convenience of service. A comparison of the rankings of attributes among the three transits shows that BRT and conventional bus have many more similarities than metro.

If transit agencies have a limited budget for improving quality of service of existing transit in Guangzhou, which attributes should be prioritized? The agencies should first consider the attributes that are relatively more important according to the model in Table 4 and relatively less satisfying based on the ranking in Table 3. The marginal cost of improving a more satisfying attribute is much higher than that of improving a less satisfying attribute. Improving a less important attribute makes a smaller contribution to the overall satisfaction than improving a more important attribute. If we use the median (7.5) as the threshold, transit agencies should improve comfort while waiting, service reliability, and safety while riding for BRT; comfort while waiting, service reliability, customer service, and travel time for conventional bus; and comfort while riding and convenience of service for metro. 


\subsection{Factors affecting differences in overall satisfaction}

The overall satisfaction differs among BRT, conventional bus, and metro. Here we identify service attributes that contribute to the differences. Here we focus on the difference between BRT and conventional bus and the difference between BRT and metro. We develop a bivariate ordered probit model using the "cmp" module. The model development procedure is as follows. We first compute the difference in the overall satisfaction between BRT and bus, which ranges from -4 to 4 . Because some values have only a few observations, we convert the difference into a four-point ordinal variable, which is one of the dependent variables in the bivariate model. Then, for each of the 14 attributes, we compute and standardize the difference between BRT and bus. The differences for the 14 attributes are the independent variables. Similarly, we construct the dependent and independent variables for the difference between BRT and metro. Socio-demographic and trip-related variables are not included because they cancel out in a model for difference. We remove the variables insignificant at the 0.05 level in both models.

Table 4: Variables affecting overall satisfaction

\begin{tabular}{|c|c|c|c|c|c|c|c|c|c|}
\hline \multirow{2}{*}{ Variables } & \multicolumn{3}{|c|}{ BRT } & \multicolumn{3}{|c|}{ Bus } & \multicolumn{3}{|c|}{ Metro } \\
\hline & Beta & $P$-value & & Beta & $P$-value & & Beta & $P$-value & \\
\hline Ease of use & 0.277 & 0.000 & 1 & 0.423 & 0.000 & 1 & 0.242 & 0.000 & 1 \\
\hline Safety while riding & 0.260 & 0.000 & 2 & 0.238 & 0.000 & 2 & 0.179 & 0.000 & 6 \\
\hline Comfort while waiting & 0.187 & 0.000 & 3 & 0.198 & 0.000 & 3 & 0.184 & 0.000 & 5 \\
\hline Convenience of service & 0.186 & 0.000 & 4 & 0.170 & 0.000 & 4 & 0.219 & 0.000 & 3 \\
\hline Door-to-door travel time & 0.161 & 0.000 & 5 & 0.116 & 0.001 & 8 & 0.195 & 0.000 & 4 \\
\hline Reliability of service & 0.130 & 0.000 & 6 & 0.148 & 0.000 & 5 & 0.160 & 0.000 & 7 \\
\hline Frequency of service & 0.113 & 0.001 & 7 & -0.031 & 0.390 & 11 & 0.104 & 0.002 & 8 \\
\hline Other riders & 0.108 & 0.001 & 8 & 0.118 & 0.001 & 7 & 0.079 & 0.024 & 9 \\
\hline Comfort while riding & 0.108 & 0.002 & 9 & 0.102 & 0.007 & 9 & 0.238 & 0.000 & 2 \\
\hline $\begin{array}{l}\text { Avoid stress/cost of car } \\
\text { use }\end{array}$ & 0.096 & 0.004 & 10 & 0.086 & 0.011 & 10 & 0.036 & 0.260 & 10 \\
\hline Customer service & 0.075 & 0.039 & 11 & 0.131 & 0.001 & 6 & 0.011 & 0.773 & 11 \\
\hline Access by BRT & & & & & & & 0.344 & 0.031 & \\
\hline Access by bus & & & & & & & -0.210 & 0.022 & \\
\hline Egress by motorcycle & -0.632 & 0.040 & & & & & & & \\
\hline Bus rider & & & & 0.131 & 0.044 & & & & \\
\hline Number of observations & 1,438 & & & & & & & & \\
\hline Rho_bus_BRT & 0.419 & 0.000 & & & & & & & \\
\hline Rho_bus_metro & 0.227 & 0.000 & & & & & & & \\
\hline Rho_BRT_metro & 0.490 & 0.000 & & & & & & & \\
\hline
\end{tabular}

Thresholds for ordered probit models are omitted; all are significant at the 0.001 level.

Table 5 present model results. The correlation between the error terms is significantly different from zero, implying that a bivariate model is appropriate. Hours of service, travel cost, safety while at station/stop, avoid stress/cost of car use are insignificant in any models. Service frequency is insignificant in the BRT-bus model and other rider is marginally significant in the BRT-metro model. Among the nine significant variables, ease of use, safety while riding, and convenience of service are the most important variables that contribute to the difference between BRT and bus. For the BRT-metro pair, the top-three variables are ease of use, comfort while riding, and convenience of service. Therefore, if the goal is to minimize the difference between BRT and metro, transit agencies should first consider improving these three attributes of BRT. 
Table 5: Models for the difference in overall satisfaction

\begin{tabular}{|l|c|c|c|c|c|c|}
\hline \multirow{2}{*}{ Variables } & \multicolumn{3}{|c|}{ BRT-Bus } & \multicolumn{3}{c|}{ BRT-Metro } \\
\cline { 2 - 8 } & Beta & P-value & Ranking & Beta & P-value & Ranking \\
\hline Ease of use & 0.238 & 0.000 & 1 & 0.240 & 0.000 & 1 \\
\hline Safety while riding & 0.208 & 0.000 & 2 & 0.127 & 0.001 & 6 \\
\hline Convenience of service & 0.193 & 0.000 & 3 & 0.195 & 0.000 & 3 \\
\hline Comfort while waiting & 0.147 & 0.000 & 4 & 0.141 & 0.000 & 5 \\
\hline Comfort while riding & 0.122 & 0.000 & 5 & 0.212 & 0.000 & 2 \\
\hline Other riders & 0.121 & 0.000 & 6 & 0.069 & 0.069 & 10 \\
\hline Door-to-door travel time & 0.111 & 0.000 & 7 & 0.173 & 0.000 & 4 \\
\hline Customer service & 0.103 & 0.002 & 8 & 0.093 & 0.021 & 8 \\
\hline Reliability of service & 0.096 & 0.003 & 9 & 0.097 & 0.012 & 7 \\
\hline Frequency of service & 0.040 & 0.233 & 10 & 0.078 & 0.037 & 9 \\
\hline \multicolumn{7}{|l|}{} \\
\hline Number of observations & 1,431 & \multicolumn{7}{|l|}{0.293} & 0.000 & & & & \\
\hline Rho & -0.293 & & & \\
\hline
\end{tabular}

Thresholds for ordered probit models are omitted; all are significant at the 0.001 level.

\section{Conclusions}

Using Guangzhou BRT as a case, this paper explores transit riders' satisfaction with BRT and compares BRT with conventional bus and metro service. Among the 14 service attributes tested here, riders are most satisfied with travel cost, ease of use, and travel time of the BRT, and least satisfied with other riders, customer service, and comfort while riding. Perceived ease of use, safety while riding, and comfort while waiting are the most important among attributes that contribute to the overall satisfaction with BRT. This suggests that planners should prioritize the three attributes when developing a new BRT service, subject to an assessment of the relative cost effectiveness of their implementation. Specifically, to improve ease of use, transit agencies can provide up-to-date timetables and maps, implement at-stop and on-board real-time information systems, offer stop announcement systems, and develop apps to allow smartphone access to traveler information (Dziekan 2008). To enhance safety while riding, the agencies shall train and reinforce drivers' behaviors related to safe operation of buses and set reasonable rules for run cutting and restrict long platform hours and spreads to prevent fatigue driving (Litman forthcoming). Further, using dedicated right-of-way can reduce interferences from other vehicles and ensure passengers a smooth ride. Improving lighting and installing surveillance cameras on board have the potential to improve perceived security. Reducing crowding can help prevent criminal activities (Carr and Spring 1993). To improve comfort while waiting at stations, the agencies shall provide basic amenities such as shelters and benches. The agencies should install trash receptacles and keep cleanliness of the stations. Additional amenities such as heating/cooling systems and vending facilities are also desirable (TCRP 2003). Transit agencies should also set a high standard for convenience of service, travel time, service reliability and frequency. On the other hand, comfort while waiting, service reliability, and safety while riding tend to be the more effective strategies that Guangzhou transit agencies should consider to improve the existing BRT service.

The data demonstrate that transit riders are most satisfied with metro, followed by BRT and conventional bus. That is, Guangzhou BRT does offer a better quality of service than conventional bus. Multivariate analyses show that the top-five attributes that contribute to the difference in the overall satisfaction between BRT and metro are ease of use, comfort while riding, convenience of service, travel time, and comfort while waiting. To reduce the gap, transit agencies should improve BRT service along 
these dimensions, also subject to an assessment of the relative cost effectiveness of their implementation. Specifically, to enhance comfort while riding, transit agencies should reduce crowding by increasing service frequency during peak hours, keep cleanliness of vehicles, and adopt buses with climate-control systems (Litman 2008). The agencies can also subsidize technology innovations such as active suspension and connected dampers to ensure a smooth ride (Kaldas and Soliman 2013). To improve convenience of service (i.e., catchment areas), transit agencies should develop a network of BRT service and/or integrate with existing transit systems (Lai and Chen 2011). Bike sharing and causal carpooling can be effective to bridge the "first/last mile" connection to transit (Lesh 2013). There are many ways to reduce BRT travel time. For example, dedicated right-of-way, transit signal priority, timed transfer, increasing stop spacing, and other bus preferential treatments (TCRP 2003).

A comparison of influential service attributes between this study and previous studies shows that they differ for different countries (Baltes 2003; Tyrinopoulos and Antoniou 2008). Therefore, the results obtained from developed countries may not be generalizable to developing countries. The blossom of BRT investments in developing countries calls for additional research in different contexts.

\section{$5 \quad$ Acknowledgements}

This study is sponsored by the National Natural Science Foundation of China (No.41171139 and 41130747) and the US National Science Foundation PIRE project (1243535). Jieyu Liu helped supervise data collection. 


\section{References}

Adebambo, S. and I. T. Adebayo. 2009. Impact of bus rapid transit system (BRT) on passengers' satisfaction in Lagos Metropolis, Nigeria. International Journal of Creativity and Technical Development 1: 106-122.

Baltes, M. R. 2003. The importance customers place on specific service elements of bus rapid transit. Journal of Public Transportation 6(4): 1-19.

Ben-Akiva, M., and T. Morikawa. 2002. Comparing ridership attraction of rail and bus. Transport Policy 9(2): 107-116.

Cain, A., J. Flynn, M. McCourt, and T. Reyes. 2009. Quantifying the Importance of Image and Perception to Bus Rapid Transit. Tampa, FL: National Bus Rapid Transit Institute, Center for Urban Transportation Research, University of South Florida and Redhill Group, Inc.

Carr, K., and G. Spring. 1993. Public transport safety: A community right and a communal responsibility. Crime Prevention Studies 1: 147-155.

Currie, G. 2005. The demand performance of bus rapid transit. Journal of Public Transportation 8(1): $41-55$.

Daykin, A. R., and P. G. Moffatt. 2002. Analyzing ordered responses: A review of the ordered probit model. Understanding Statistics 1(3): 157-166.

Deng, T., and J. D. Nelson. 2012. The perception of bus rapid transit: A passenger survey from Beijing Southern Axis BRT Line 1. Transportation Planning and Technology 35(2): 201-219.

Dziekan, K. 2008. Ease-of-use in public transportation-A user perspective on information and orientation aspects. In Traffic and Transport Planning, Infrastructure and Planning. Stockholm: Royal Institute of Technology.

Garrett, M., and B. Taylor. 1999. Reconsidering social equity in public transit. Berkeley Planning Journal 13(6-27).

Kaldas, M., and A. Soliman. 2013. Improvement of Bus Ride Comfort via Active Suspension and Connected Dampers. SAE Technical Paper 2013-01-0990, 2013. doi:10.4271/2013-01-0990.

Lai, W.-T., and C.-F. Chen. 2011. Behavioral intentions of public transit passengers-The roles of service quality, perceived value, satisfaction and involvement. Transport Policy 18(2): 318-325.

Lesh, M. C. 2013. Innovative concepts in first-last mile connections to public transportation, In The Third International Conference on Urban Transportation Systems, edited by S. Jones. Paris, France: American Society of Civil Engineers.

Levinson, H., S. Zimmerman, J. Clinger, and J. Gast. 2003a. Bus rapid transit: Synthesis of case studies. Transportation Research Record 1841:1-11.

Levinson, H., S. Zimmerman, J. Clinger, S. Rutherford, R. Smith, J. Racknell, and R. Soberman. 2003b. Bus Rapid Transit. Washington, DC: Transit Cooperative Research Program.

Litman, T. 2008. Valuing transit service quality improvements. Journal of Public Transportation 11(2): 43-63.

Litman, T. Forthcoming. Safer than you think: Revising the transit safety narrative. Journal of Public Transportation.

Luck, A. 2001. Bus and Bus Stop Designs Related to the Perception of Crime. Washington, DC: Federal Transit Administration.

Mahmoudi, S. M., F. Verdinejad, G. Jandaghi, and A. M. Mughari. 2010. Analysis and establishment of bus rapid transit (BRT) on customer satisfaction in Tehran. African Journal of Business Management 4(12): 2514-2519. 
Roodman, D. 2011. Estimating fully observed recursive mixed-process models with cmp. Stata Journal 11(2): 159-206.

TCRP. 2000. Enhancing the Visibility and Image of Transit in the United States and Canada. Washington, DC: Transit Cooperative Research Program.

TCRP. 2003. Transit Capacity and Quality of Service Manual. 2nd Edition. Washington, DC: Transit Cooperative Research Program.

Tyrinopoulos, Y., and C. Antoniou. 2008. Public transit user satisfaction: Variability and policy implications. Transport Policy 15(4): 260-272. 